\title{
Evaluation of scientific publications with hesitant fuzzy uncertain linguistic and semantic information
}

\author{
Hao $\mathrm{Xu}^{\mathrm{a}}$, Lining Xing ${ }^{\mathrm{b}}$ and Lan Huang ${ }^{\mathrm{a}, *}$ \\ ${ }^{a}$ College of Computer Science and Technology, Jilin University, Changchun, P.R. China \\ ${ }^{\mathrm{b}}$ Department of Management Science and Engineering, College of Information System and Management, National \\ University of Defense Technology, Changsha, P.R. China
}

\begin{abstract}
Scientific and technological papers play a fundamental role in the scientific and technological innovation of countries. The quality control of scientific and technological articles is vital to the journals and management of personnel. This paper investigates multiple attribute decision-making problems with the application of hesitant fuzzy uncertain linguistic information. Motivated by the ideal traditional I-COA operator, an induced hesitant fuzzy uncertain linguistic correlated averaging (IHFULCA) operator is developed. The IHFULCA operator was used to develop approaches to solve hesitant fuzzy uncertain linguistic multiple attribute decision-making problems. Finally, a practical example for evaluating the academic value of scientific and technological papers is provided to verify the developed approach and demonstrate its practicality and effectiveness.
\end{abstract}

Keywords: Multiple attribute decision-making, hesitant fuzzy uncertain linguistic values, scientific publications

\section{Introduction}

Enhancing innovative ability is a core national development strategy necessary to the construction of an innovative country, and is the key to improving overall national strength $[29,30]$. The process of improving independent innovation must be accompanied by the realization of scientific and technological achievements. Transfer capacity of technological innovation and technology is an area of core competitiveness between countries [21, 22]. While technical papers remain an important means by which innovation and technology researchers disseminate their ideas, they are

\footnotetext{
${ }^{*}$ Corresponding author. Lan Huang, College of Computer Science and Technology, Jilin University, Changchun 130012, P.R. China. E-mail: huanglan@jlu.edu.cn.
}

also a way for scientific and technological achievements to be transformed into productivity [1]. Cost and time effectiveness are issues common to much of this work $[2,18,32]$.

The emergence and popularization of network technology has enabled the wider dissemination of scientific papers. Information technology is now widely used to construct online platforms on which papers can appear [22, 31]. The Internet has created an information superhighway that breaks through the traditional modes of information transmission, and makes academic resources available to a wider global audience in a more permanent way [23]. Researchers can access the latest research and conduct academic exchanges quickly and efficiently [17]. China was late to the movement with its Open Access policy and publication of scientific papers $[13,16]$. To date, China has not yet 
perfected the publication of scientific papers using the academic evaluation influence system [10, 12]. This makes it difficult to perform objective and comprehensive assessments of the academic influence of published scientific papers [11]. Online papers published in many networks are not readily recognized, resulting in the loss of a large number of high-quality, highly impactful research results, which in turn affects the publication of scientific papers and their further development and expansion in relevant fields [9].

In recent years, the field of information science has focused on exploring and establishing an impact evaluation index and evaluation system for published scientific papers [26, 33]. This paper evaluates the impact evaluation of academic papers published on the Internet and to establish standardized scientific evaluation criteria $[8,19,20]$. This study aims to construct impact assessment indices for scientific papers, which can provide a reference for the evaluation of academic resources, and ultimately ensure that scientific papers published in our country can induce real social change $[14,55]$. Simultaneously, this project is important to the realization of the effective configuration of scientific resources, enhancing efficient utilization of scientific resources and accelerating the transfer of research findings into productivity $[3,4,27]$. The problem of evaluating the academic value of scientific and technological papers with hesitant fuzzy uncertain linguistic information is the complexity of multiple attribute decision-making problems [6, 25, 28].

The peer review, influential factor and citation evaluation systems that are common worldwide are all specific to the journal in which the thesis is published and the citation, which presents shortcomings and limitations: there is a lack of evaluation of the thesis itself, which is influenced by the subject difference $[5,7]$. Therefore, it is urgent to establish a comprehensive and systematic thesis evaluation system, so as to overcome the limitations of the existing evaluation system and take into account the demand of many kinds of theses such as open access. For this reason, this paper investigates multiple attribute decision-making problems with hesitant fuzzy uncertain linguistic information.

The research motivations of this paper can be summarized as follows. Motivated by the ideal traditional I-COA operator, an induced hesitant fuzzy uncertain linguistic correlated averaging (IHFULCA) operator is developed. The IHFULCA operator is used to develop an approach to solve hesitant fuzzy uncertain linguistic multiple attribute decision-making problems.

\section{Proposed approach}

Scientific and technological theses reflect the research level and achievements of the researchers, and the evaluation of the theses of scientific research personnel can potentially reflect their academic level. At present, the academic theses evaluation is an important means for scientific research institutes, higher education and government departments to conduct performance assessments, title evaluation and determine scientific award to the scientific research personnel. This work is of significance, but there is also great controversy, which is primarily reflected in the evaluation method of academic theses. This paper investigates multiple attribute decision-making problems with hesitant fuzzy uncertain linguistic information.

Definition 1. Given a fixed set $X$ and an uncertain linguistic set $\tilde{S}$, then a hesitant fuzzy uncertain linguistic set (HFULS) of $X$ is in terms of a function that when applied to $X$, returns a subset of $[0,1]$. To be easily understood, the HFULS can be expressed by mathematical symbols as follows:

$$
\tilde{A}=\left(\left\langle x, \tilde{s}_{\theta(x)}, h_{\tilde{A}}(x)\right\rangle \mid x \in X\right)
$$

where $h_{A}(x)$ is a set of values between $[0,1]$, denoting the possible membership degree of the element $x \in X$ to the uncertain linguistic set $\tilde{s}_{\theta(x)}$.

Definition 2. Let $\tilde{s}_{1}=\left[s_{\alpha_{1}}, s_{\beta_{1}}\right], \tilde{s}_{2}=\left[s_{\alpha_{2}}, s_{\beta_{2}}\right]$ be two uncertain linguistic variables, and let len $\left(\tilde{s}_{1}\right)=\beta_{1}-$ $\alpha_{1}$, len $\left(\tilde{s}_{2}\right)=\beta_{2}-\alpha_{2}$. Then, the degree of possibility of $\tilde{s}_{1} \geq \tilde{s}_{2}$ is defined as

$$
\begin{aligned}
p & \left(\tilde{s}_{1} \geq \tilde{s}_{2}\right) \\
& =\frac{\max \left(0, \operatorname{len}\left(\tilde{s}_{1}\right)+\operatorname{len}\left(\tilde{s}_{2}\right)-\max \left(\beta_{2}-\alpha_{1}, 0\right)\right)}{\operatorname{len}\left(\tilde{s}_{1}\right)+\operatorname{len}\left(\tilde{s}_{2}\right)}
\end{aligned}
$$

Definition 3. Let $f$ be a positive real-valued function of $X$ and $m$ be a fuzzy measure of $X$. The induced Choquet ordered averaging operator of dimension $n$ is a function I-COA : $\left(R^{+} \times R^{+}\right) \rightarrow R^{+}$, which is defined to aggregate the set of a second argument $\left\langle u_{1}, f_{1}\right\rangle,\left\langle u_{2}, f_{2}\right\rangle, \ldots,\left\langle u_{n}, f_{n}\right\rangle$ according to the following expression:

$$
\begin{gathered}
\mathrm{I}-\mathrm{COA}_{m}\left(\left\langle u_{1}, f_{1}\right\rangle,\left\langle u_{2}, f_{2}\right\rangle, \ldots,\left\langle u_{n}, f_{n}\right\rangle\right) \\
=\sum_{j=1}^{n} f_{\sigma(j)}\left[m\left(A_{\sigma(j)}\right)-m\left(A_{\sigma(j-1)}\right)\right]
\end{gathered}
$$


where $(\sigma(1), \sigma(2), \ldots, \sigma(n))$ is a permutation of $(1,2, \ldots, n)$, such that $u_{\sigma(i-1)} \geq u_{\sigma(i)}$ for all $j=$ $2, \ldots, n$, i.e., $\left\langle u_{\sigma(j)}, f_{\sigma(j)}\right\rangle$ is the 2-tuple, with $u_{\sigma(j)}$ the $j$ th largest value in the set $\left(u_{1}, u_{2}, \ldots, u_{n}\right), A_{\sigma(k)}=$ $\left\{x_{\sigma(j)} \mid j \leq k\right\}$, for $k \geq 1$, and $A_{\sigma(0)}=\phi$.

The following section develops the IHFULCA operator based on the I-COA operator.

Definition 4. Let $\left\langle u_{j}, \tilde{a}_{j}\right\rangle=\left\langle u_{j},\left(\tilde{s}_{\theta\left(a_{j}\right)}, h\left(a_{j}\right)\right)\right\rangle=$ $\left\langle u_{j},\left\langle\left[s_{\theta L}\left(\tilde{a}_{j}\right), s_{\theta}\left(\tilde{a}_{j}\right)\right],\left(\tilde{s}_{\theta\left(a_{j}\right)}, h\left(a_{j}\right)\right)\right\rangle\right\rangle$ be a collection of 2-tuples of $X$, and $\mu$ be a fuzzy measure of $X$. Then,

$$
\begin{gathered}
\operatorname{IHFULCA}_{\mu}\left(\left\langle u_{1}, \tilde{a}_{1}\right\rangle,\left\langle u_{2}, \tilde{a}_{2}\right\rangle, \ldots,\left\langle u_{n}, \tilde{a}_{n}\right\rangle\right) \\
=\bigoplus_{j=1}^{n}\left(\left(\mu\left(A_{\sigma(j)}\right)-\mu\left(A_{\sigma(j-1)}\right)\right) \tilde{a}_{\sigma(j)}\right)
\end{gathered}
$$

where $w=\left(w_{1}, w_{2}, \ldots, w_{n}\right)^{T}$ is a weighting vector such that $w_{j}>0, \sum_{j=1}^{n} w_{j}=1, j=1,2, \ldots, n, \tilde{a}_{\sigma(j)}$ is the $\tilde{a}_{j}$ value of the IHFULCA pair $\left\langle u_{i}, \tilde{a}_{i}\right\rangle$ having the $j$ th largest $u_{i}\left(u_{i} \in[0,1]\right), u_{i}$ in $\left\langle u_{i}, \tilde{a}_{i}\right\rangle$ is referred to as the order-inducing variable, and $\tilde{a}_{i}$ is referred to as the hesitant fuzzy uncertain linguistic arguments.

With the operation of hesitant fuzzy uncertain linguistic variables, the IHFULCA operator can be transformed into the following form by induction on $n$ :

$$
\begin{aligned}
& \operatorname{IHFULCA}_{\mu}\left(\left\langle u_{1}, \tilde{a}_{1}\right\rangle,\left\langle u_{2}, \tilde{a}_{2}\right\rangle, \ldots,\left\langle u_{n}, \tilde{a}_{n}\right\rangle\right) \\
& =\bigoplus_{j=1}^{n}\left(\left(\mu\left(A_{\sigma(j)}\right)-\mu\left(A_{\sigma(j-1)}\right)\right) \tilde{a}_{\sigma(j)}\right) \\
& =\left\langle\left[\sum_{j=1}^{n}\left(\mu\left(A_{\sigma(j)}\right)-\mu\left(A_{\sigma(j-1)}\right)\right) s_{\theta} L\left(\tilde{a}_{\sigma(j)}\right),\right.\right. \\
& \left.\sum_{j=1}^{n}\left(\mu\left(A_{\sigma(j)}\right)-\mu\left(A_{\sigma(j-1)}\right)\right) s_{\theta^{R}\left(\tilde{a}_{\sigma(j)}\right)}\right],
\end{aligned}
$$

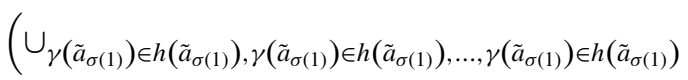

$$
\begin{aligned}
& \left.\left.\left\{1-\prod_{j=1}^{n}\left(1-\gamma\left(\tilde{a}_{\sigma(j)}\right)\right)^{\left(\mu\left(A_{\sigma(j)}\right)-\mu\left(A_{\sigma(j-1)}\right)\right)}\right\}\right)\right\rangle
\end{aligned}
$$

where $w=\left(w_{1}, w_{2}, \ldots, w_{n}\right)^{T}$ is a weighting vecto, such that $w_{j}>0, \sum_{j=1}^{n} w_{j}=1, j=1,2, \ldots, n, \tilde{a}_{\sigma(j)}$ is the $\tilde{a}_{j}$ value of the IHFULCA pair $\left\langle u_{i}, \tilde{a}_{i}\right\rangle$ having the $j$ th largest $u_{i}\left(u_{i} \in[0,1]\right), u_{i}$ in $\left\langle u_{i}, \tilde{a}_{i}\right\rangle$ is referred to as the order-inducing variable and $\tilde{a}_{i}$ is referred to as the hesitant fuzzy uncertain linguistic arguments.

The IHFULCA operator is applied to multiple attribute decision-making in order to evaluate the academic value of scientific publications with hesitant fuzzy uncertain linguistic and semantic information. Let $A=\left\{A_{1}, A_{2}, \ldots, A_{m}\right\}$ be a discrete set of alternatives, and $G=\left\{G_{1}, G_{2}, \ldots, G_{n}\right\}$ be the state of nature. If the decision-makers provide several values for the alternative $A_{i}$ under the state of nature $G_{j}$ with respect to $\tilde{s}_{\theta_{i j}}$ with anonymity, these values can be considered as a hesitant fuzzy uncertain linguistic element $\left\langle\tilde{s}_{\theta_{i j}}, h_{i j}\right\rangle$.

In the following section, the IHFULCA operator is applied to MADM problems in order to evaluate the academic value of scientific and technological papers with hesitant fuzzy uncertain linguistic information.

Step 1. The decision information given in matrix $H$, and the IHFULCA operator are used as follows:

$$
\begin{aligned}
& \tilde{h}_{i}=\left(\left\langle\tilde{s}_{\theta_{i}}, h_{i}\right\rangle\right) \\
& =\operatorname{IHFULCA}_{w}\left(\left\langle u_{i 1}, \tilde{h}_{i 1}\right\rangle,\left\langle u_{2}, \tilde{h}_{i 2}\right\rangle, \ldots,\left\langle u_{i n}, \tilde{h}_{i n}\right\rangle\right) \\
& =\bigoplus_{j=1}^{n}\left(\left(\mu\left(A_{\sigma(j)}\right)-\mu\left(A_{\sigma(j-1)}\right)\right) \tilde{h}_{\sigma(i j)}\right) \\
& =\left\langle\left[\sum_{j=1}^{n}\left(\mu\left(A_{\sigma(j)}\right)-\mu\left(A_{\sigma(j-1)}\right)\right) s_{\theta_{\sigma(i j)}^{L}},\right.\right. \\
& \left.\sum_{j=1}^{n}\left(\mu\left(A_{\sigma(j)}\right)-\mu\left(A_{\sigma(j-1)}\right)\right) s_{\theta_{\sigma(i j)}^{R}}\right] \text {, } \\
& \left(\cup_{\gamma_{\sigma(i 1)} \in h_{\sigma(i 1)}, \gamma_{\sigma(i 2)} \in h_{\sigma(i 2)}, \ldots, \gamma_{\sigma(i n)} \in h_{\sigma(i n)}}\right.
\end{aligned}
$$

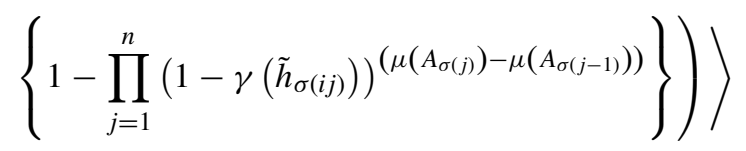

$$
\begin{aligned}
& i=1,2, \ldots, m \text {. }
\end{aligned}
$$

Step 2. Calculate the scores $S\left(\tilde{h}_{i}\right) \quad(i=1,2, \ldots, m)$ of the overall hesitant fuzzy uncertain linguistic values $\tilde{h}_{i}(i=1,2, \ldots, m)$.

Step 3. To rank these, the scores $S\left(\tilde{h}_{i}\right)(i=1,2, \ldots, m)$ all of the overall hesitant fuzzy uncertain linguistic preference values $\tilde{h}_{i}(i=1,2, \ldots, m)$ are first compared with all the $S\left(\tilde{h}_{j}\right)(j=1,2, \ldots, m)$.

Step 4. Rank all the alternatives $A_{i}(i=1,2, \ldots, m)$, and select the best one(s) in accordance with $S\left(\tilde{h}_{i}\right)(i=1,2, \ldots, m)$. 
Table 1

Hesitant fuzzy uncertain linguistic decision matrix

\begin{tabular}{lllll}
\hline & $\mathrm{G}_{1}$ & $\mathrm{G}_{2}$ & $\mathrm{G}_{3}$ & $\mathrm{G}_{4}$ \\
\hline $\mathrm{A}_{1}$ & $<\left[\mathrm{s}_{2}, \mathrm{~s}_{3}\right],(0.5,0.6)>$ & $<\left[\mathrm{s}_{4}, \mathrm{~s}_{5}\right],(0.3,0.5)>$ & $<\left[\mathrm{s}_{2}, \mathrm{~s}_{3}\right],(0.7,0.8)>$ & $<\left[\mathrm{s}_{1}, \mathrm{~s}_{2}\right],(0.5)>$ \\
$\mathrm{A}_{2}$ & $<\left[\mathrm{s}_{3}, \mathrm{~s}_{4}\right],(0.3,0.4)>$ & $<\left[\mathrm{s}_{2}, \mathrm{~s}_{3}\right],(0.6)>$ & $<\left[\mathrm{s}_{4}, \mathrm{~s}_{5}\right],(0.3,0.4)>$ & $<\left[\mathrm{s}_{2}, \mathrm{~s}_{3}\right],(0.4)>$ \\
$\mathrm{A}_{3}$ & $<\left[\mathrm{s}_{2}, \mathrm{~s}_{3}\right],(0.4,0.5)>$ & $<\left[\mathrm{s}_{4}, \mathrm{~s}_{5}\right],(0.3,0.6)>$ & $<\left[\mathrm{s}_{2}, \mathrm{~s}_{3}\right],(0.1,0.5)>$ & $<\left[\mathrm{s}_{4}, \mathrm{~s}_{5}\right],(0.4,0.5>$ \\
$\mathrm{A}_{4}$ & $<\left[\mathrm{s}_{5}, \mathrm{~s}_{6}\right],(0.2,0.3)>$ & $<\left[\mathrm{s}_{3}, \mathrm{~s}_{4}\right],(0.4)>$ & $<\left[\mathrm{s}_{1}, \mathrm{~s}_{2}\right],(0.4,0.7)>$ & $<\left[\mathrm{s}_{2}, \mathrm{~s}_{3}\right],(0.4,0.7)>$ \\
$\mathrm{A}_{5}$ & $<\left[\mathrm{s}_{2}, \mathrm{~s}_{3}\right],(0.4,0.5)>$ & $<\left[\mathrm{s}_{3}, \mathrm{~s}_{4}\right],(0.5,0.6)>$ & $<\left[\mathrm{s}_{1}, \mathrm{~s}_{2}\right],(0.4,0.6)>$ & $<\left[\mathrm{s}_{3}, \mathrm{~s}_{4}\right],(0.3,0.6)>$ \\
\hline
\end{tabular}

\section{Experimental results}

At present, the issues of scientific evaluation are most concentrated in the evaluation of institutions, scholars and academic journals, and indicators such as the $\mathrm{H}$ index, $\mathrm{G}$ index and influential factors are widely used for the above evaluation. However, there is seldom research conducted on the evaluation of a scientific and technological thesis. The evaluation of scientific and technological theses is primarily conducted according to methods of peer review, citation analysis and influential factors regarding the specific journal. Peer review is a relatively common academic thesis evaluation method, but has significant time costs, has the potential for strong interference and is influenced by many subjective elements such as the selection of experts, personal hobbies, social relationships and subject background, introducing strong randomness and subjectivity. When the evaluation of many theses of different subject fields is necessary, it is difficult to obtain appropriate experts. Citation analysis is conducted to evaluate the frequency of the cited thesis. In addition, the influential factor is established on the basis of citation frequency, and will inevitably be influenced by the subject difference; for example, the influential factor of life science is higher than that of journals of mechanics.

With the rapid development of computer and communication technology, library resources in the 21st century have radically changed from paper-based to digital resources. Digital resources, which can be readily shared, updated and developed, have had an important effect on teaching in schools and on scientific research. There are costs associated with an the purchasing of digital resources by an academic library, and these may be higher than the cost of paper-based resources. The purchase of digital resources has become an important part of academic library management. Many academic and scientific research organizations are actively developing evaluations of digital resources. In this section, the IHFULCA operator is applied multiple attribute decision-making in order to evaluate the academic value of scientific and technological papers with hesitant fuzzy uncertain linguistic information. A set of five different types of scientific and technological papers were used, $A_{i}(i=1,2,3,4,5)$, which were evaluated according to four attributes: (1) innovation $\left(\mathrm{G}_{1}\right)$; (2) scientific value $\left(\mathrm{G}_{2}\right)$; (3) application prospects $\left(G_{3}\right)$; and $(4)$ practical significance $\left(G_{4}\right)$. To avoid influencing one another, decision-makers were required to independently and anonymously evaluate the scientific and technological papers $A_{i}(i=1,2,3,4,5)$ based on the above mentioned attributes. The decision matrix $H=\left(\tilde{h}_{i j}\right)_{5 \times 4}=\left(\left\langle\tilde{s}_{i j}, h_{i j}\right\rangle\right)_{5 \times 4}$ is presented in Table 1.

This approach was used to obtain the most desirable scientific and technological papers.

Step 1. Suppose the fuzzy measure of attribute $G_{j}$ $(j=1,2 \ldots, n)$ and attribute sets of $G$ as follows:

$$
\begin{aligned}
& \mu\left(G_{1}\right)=0.30, \mu\left(G_{2}\right)=0.24, \\
& \mu\left(G_{3}\right)=0.29, \mu\left(G_{4}\right)=0.20 \\
& \mu\left(G_{1}, G_{2}\right)=0.62, \mu\left(G_{1}, G_{3}\right)=0.53, \\
& \mu\left(G_{1}, G_{4}\right)=0.50, \mu\left(G_{2}, G_{3}\right)=0.40 \\
& \mu\left(G_{2}, G_{4}\right)=0.45, \mu\left(G_{3}, G_{4}\right)=0.50, \\
& \mu\left(G_{1}, G_{2}, G_{3}\right)=0.70, \mu\left(G_{1}, G_{2}, G_{4}\right)=0.80 \\
& \mu\left(G_{1}, G_{3}, G_{4}\right)=0.74, \mu\left(G_{2}, G_{3}, G_{4}\right)=0.68, \\
& \mu\left(G_{1}, G_{2}, G_{3}, G_{4}\right)=1.00
\end{aligned}
$$

Step 2. The experts used order-inducing variables to represent the complex attitudinal character involving the opinions of different decision-makers; results are shown in Table 2.

Table 2

Inducing variables

\begin{tabular}{lllll}
\hline & $\mathrm{G}_{1}$ & $\mathrm{G}_{2}$ & $\mathrm{G}_{3}$ & $\mathrm{G}_{4}$ \\
\hline $\mathrm{A}_{1}$ & 16 & 14 & 18 & 11 \\
$\mathrm{~A}_{2}$ & 20 & 22 & 21 & 16 \\
$\mathrm{~A}_{3}$ & 16 & 15 & 20 & 17 \\
$\mathrm{~A}_{4}$ & 13 & 19 & 13 & 16 \\
$\mathrm{~A}_{5}$ & 18 & 20 & 17 & 22 \\
\hline
\end{tabular}


Step 3. The decision information given in matrix $H$ and the IHFULCA operator were used to obtain the scores $S\left(\tilde{h}_{i}\right)(i=1,2,3,4,5)$ of the overall hesitant fuzzy uncertain linguistic preference values $h_{i}$ $(i=1,2,3,4,5)$.

$$
\begin{aligned}
& S\left(\tilde{h}_{1}\right)=\left[\mathrm{s}_{1.21}, \mathrm{~s}_{2.14}\right], S\left(\tilde{h}_{2}\right)=\left[\mathrm{s}_{2.56}, \mathrm{~s}_{3.78}\right], \\
& S\left(\tilde{h}_{3}\right)=\left[\mathrm{s}_{0.74}, \mathrm{~s}_{1.35}\right], S\left(\tilde{h}_{4}\right)=\left[\mathrm{s}_{1.28}, \mathrm{~s}_{3.78}\right], \\
& S\left(\tilde{h}_{5}\right)=\left[\mathrm{s}_{0.75}, \mathrm{~s}_{3.59}\right]
\end{aligned}
$$

Step 4. All five scientific and technological papers $A_{i}(i=1,2,3,4,5)$ were ranked in accordance with the scores $S\left(\tilde{h}_{i}\right)(i=1,2,3,4,5)$. The ordering of scientific and technological papers was determined as follows: $A_{2} \succ A_{4} \succ A_{5} \succ A_{1} \succ A_{3}$; the best scientific and technological paper was determined to be paper $A_{2}$.

The three major retrieval journals, especially the important core journals, require relatively high quality, with regulated draft audit and use procedures. It is equivalent that the journals have been evaluated by peer experts, so they have a relatively high credibility. However, it cannot be denied that three major retrieval journals also present inferior quality. It is suggested that the state should emphasize the important role of the three major retrievals in China, organize experts of various subjects to further screen the three major retrieval journals, and form a high-quality journal group consisting of the three screened major retrieval journals and the domestic important core journals, so as to measure the academic level of the researchers.

\section{Conclusions}

In this paper, multiple attribute decision-making problems were investigated with hesitant fuzzy uncertain linguistic information. The strengths of this proposed method can be summarized as follows. Driven by the ideal traditional I-COA operator, the IHFULCA operator was developed. The IHFULCA operator was then used to develop an approach to solving hesitant fuzzy uncertain linguistic multiple attribute decisionmaking problems. A practical example of evaluating the academic value of scientific and technological papers is provided to verify the developed approach and demonstrate its practicality and effectiveness.

The weaknesses of this proposed method can be summarized as follows. The theoretical system of this method is imperfect, and the utilized empirical research is inadequate.
Future research directions can be summarized as follows. First, the basic theories of this proposed method should be improved. Second, more practical examples should be studied to demonstrate the practicality and effectiveness of this method.

\section{Conflict of interests fine tuning}

The authors declare that there is no conflict of interests regarding the publication of this article.

\section{Acknowledgments}

The authors thank the reviewers for valuable comments and constructive suggestions. We also thank the editor-in-chief, associate editor and editors for helpful suggestions. This work is supported by the National Natural Science Foundation of China (No. 61300147, 61472159, 71101150), China Postdoctoral Science Foundation (No. 2014M551185), Electronic Commerce Engineering Laboratory Project of Jilin Province (2014N143), the Science and Technology Program of Changchun (No. 14GH014), the Program for New Century Excellent Talents in University, the Youth Training Program for Innovation and Entrepreneurship Platform of Science and Technology at Hunan Province and the Outstanding Youth Fund Project of Hunan Provincial Natural Science Foundation.

\section{References}

[1] C.T. Chen, P.F. Pai and W.Z. Hung, An integrated methodology using linguistic PROMETHEE and maximum deviation method for third-party logistics supplier selection, International Journal of Computational Intelligence Systems 3 (2010), 438-451.

[2] D.H. Choi, B.S. Ahn and S.H. Kim, Multicriteria group decision making under incomplete preference judgments: Using fuzzy logic with a linguistic quantifier, International Journal of Intelligent Systems 22 (2007), 641-660.

[3] E. Szmidt and J. Kacprzyk, Using intuitionistic fuzzy sets in group decision making, Control and Cybernetics 31 (2002), 1037-1053.

[4] E. Szmidt and J. Kacprzyk, A consensus-reaching process under intuitionistic fuzzy preference relations, International Journal of Intelligent Systems 18 (2003), 837-852.

[5] F. Giunchiglia, H. Xu and A. Birukou, Scientific Knowledge Object Patterns, EuroPLoP-2010, Germany, ACM International Conference Proceeding Series, 2011.

[6] G. Deschrijver, C. Cornelis and E.E. Kerre, On the representation of intuitionistic fuzzy t-norms and t-conorms, IEEE Transactions on Fuzzy Systems 12 (2004), 45-61. 
[7] G. Deschrijver and E.E. Kerre, A generalization of operators on intuitionistic fuzzy sets using triangular norms and conorms, Notes on intuitionistic Fuzzy Sets 8 (2002), 19-27.

[8] G.W. Wei, Uncertain linguistic hybrid geometric mean operator and its Application to group decision making under uncertain linguistic environment, International Journal of Uncertainty, Fuzziness and Knowledge-Based Systems 17(2) (2009), 251-267.

[9] G.W. Wei, Hesitant Fuzzy prioritized operators and their application to multiple attribute group decision making, Knowledge-Based Systems 31 (2012), 176-182.

[10] G.W. Wei, An approach to multiple attribute group decision making with interval intuitionistic trapezoidal fuzzy information, Technological and Economic Development of Economy 18(2) (2012), 317-330.

[11] G.W. Wei and X.F. Zhao, Some induced correlated aggregating operators with intuitionistic fuzzy information and their application to multiple attribute group decision making, Expert Systems with Applications 39(2) (2012), 2026-2034.

[12] G.W. Wei and X.F. Zhao, Some dependent aggregation operators with 2-tuple linguistic information and their application to multiple attribute group decision making, Expert Systems with Applications 39 (2012), 5881-5886.

[13] G.W. Wei, X.F. Zhao and R. Lin, Generalized triangular fuzzy correlated averaging operator and their application to multiple attribute decision making, Applied Mathematical Modelling 36(7) (2012), 2975-2982.

[14] G.W. Wei, X.F. Zhao and R. Lin, Uncertain linguistic Bonferroni mean operators and their application to multiple attribute decision making, Applied Mathematical Modeling 37(7) (2013), 5277-5285.

[15] H. Xu and B. Yu, Automatic thesaurus construction for spam filtering using revised back propagation neural network, Expert Systems with Applications 37(1) (2010), 18-23.

[16] H. Xu, C.H. Zhang, Y.A. Tan and J. Lu, An improved evolutionary approach to the extended capacitated arc routing problem, Expert Systems with Applications 38(4) (2011), 4637-4641.

[17] H. Xu, P. Wan and D.W. Jin, A hybrid approach to the precision of particle-size-distribution retrieval, Information - An International Interdisciplinary Journal 15(8) (2012), 3187-3194.

[18] H.Y. Chen, L.G. Zhou and B. Han, On compatibility of uncertain additive linguistic preference relations and its application in the group decision making, Knowledge-Based Systems $\mathbf{2 4}$ (2011), 816-823.

[19] L.N. Xing, P. Rohlfshagen, Y.W. Chen and X. Yao, An evolutionary approach to the multi-depot capacitated arc routing problem, IEEE Transactions on Evolutionary Computation 14(3) (2010), 356-374.

[20] L.N. Xing, P. Rohlfshagen, Y.W. Chen and X. Yao, A hybrid ant colony optimization algorithm for the extended capacitated arc routing problems, IEEE Transactions on Systems, Man, and Cybernetics, Part B: Cybernetics 41(4) (2011), 1110-1123.

[21] L.N. Xing, Y.W. Chen and K.W. Yang, A novel mutation operator based on the immunity operation, European Journal of Operational Research 197(2) (2009), 830-833.

[22] L.N. Xing, Y.W. Chen and K.W. Yang, Multi-population interactive coevolutionary algorithm for flexible job shop scheduling problems, Computational Optimization and Applications 48(1) (2011), 139-155.

[23] L.N. Xing, Y.W. Chen, K.W. Yang, F. Hou, X.S. Shen and H.P. Cai, A hybrid approach combining an improved genetic algorithm and optimization strategies for the asymmetric traveling salesman problem, Engineering Applications of Artificial Intelligence 21(8) (2008), 1370-1380.

[24] L.N. Xing, Y.W. Chen, P. Wang, Q.S. Zhao and J. Xiong, A knowledge-based ant colony optimization for flexible job shop scheduling problems, Applied Soft Computing 10(3) (2010), 888-896.

[25] M. Grabisch, T. Murofushi and M. Sugeno, Fuzzy Measure and Integrals, New York: Physica-Verlag, 2000.

[26] R. Lin, X.F. Zhao and G.W. Wei, Models for selecting an ERP system with hesitant fuzzy linguistic information, Journal of Intelligent and Fuzzy Systems 26(5) (2014), 2155-2165.

[27] R. Sadiq and S. Tesfamariam, Environmental decision-making under uncertainty using intuitionistic fuzzy analytic hierarchy process, Stochastic Environmental Research and Risk Assessment 23 (2009), 75-91.

[28] S. Roychowdhury and B.H. Wang, On generalized Hamacher families of triangular operators, International Journal of Approximate Reasoning 19 (1998), 419-439.

[29] S.L. Chang, R.C. Wang and S.Y. Wang, Applying fuzzy linguistic quantifier to select supply chain partners at different phases of product life cycle, International Journal of Production Economics 100 (2006), 348-359.

[30] S.L. Chang, R.C. Wang and S.Y. Wang, Applying a direct multi-granularity linguistic and strategy-oriented aggregation approach on the assessment of supply performance, European Journal of Operational Research 177 (2007), 1013-1025.

[31] S.J. Chuu, Interactive group decision-making using a fuzzy linguistic approach for evaluating the flexibility in a supply chain, European Journal of Operational Research 213 (2011), 279-289.

[32] Y.H. Chen, T.C. Wang and C.Y. Wu, Multi-criteria decision making with fuzzy linguistic preference relations, Applied Mathematical Modeling 35 (2011), 1322-1330.

[33] Z.S. Xu, Uncertain linguistic aggregation operators based approach to multiple attribute group decision making under uncertain linguistic environment, Information Science $\mathbf{1 6 8}$ (2004), 171-184. 